\title{
Navigating personal and professional development through social media: a cross-sectional survey of ophthalmologists
}

Bonnie He ( $\sim$ bonnie.he@alumni.ubc.ca )

Dalhousie University https://orcid.org/0000-0002-3728-4436

\section{Stuti Tanya}

Memorial University of Newfoundland

Fiona Costello

University of Calgary

Femida Kherani

University of Calgary

Neda Shamie

Dagny Zhu

\section{Article}

Keywords: social media, women in ophthalmology, mentorship, professional development

Posted Date: January 24th, 2022

DOI: https://doi.org/10.21203/rs.3.rs-1156196/v1

License: (c) (1) This work is licensed under a Creative Commons Attribution 4.0 International License.

Read Full License 


\section{Abstract \\ Background}

Despite its popularity in ophthalmology, the role of social media as a tool for networking, mentorship, and community support amongst ophthalmologists remains unknown. The objective of this study was to elucidate how ophthalmologists use social media for personal and professional purposes.

\section{Methods}

This was a cross-sectional survey study whereby a 40-item questionnaire investigating the role of social media for personal and professional use was developed and distributed to residents, fellows and practicing ophthalmologists in Canada and the United States. Responses were analyzed using descriptive and basic statistics.

\section{Results}

149 respondents (67\% women) completed the survey, with $56 \%$ of participants between the ages of $25-35$ years old. Women were more likely to report experiencing workplace discrimination $(p<0.005)$ and worklife disharmony $(p<0.05)$ compared to men, and social media was found to be useful in overcoming those challenges $(p<0.005$ and $p<0.001$ respectively). Younger respondents ( $<45$ years old) cited more challenges with practice management $(p<0.005)$ and turned to social media for corresponding guidance $(p<0.05)$. Compared to late career ophthalmologists, trainees were more likely to report difficulties with career advancement $(p<0.05)$, practice management $(p<0.0001)$ and financial planning $(p<0.05)$, with social media beneficial for developing financial literacy $(p<0.05)$.

\section{Conclusions}

Social media is an invaluable tool for enhancing professional and personal growth among individuals in ophthalmology, particularly for women, trainees, and those early in their career stages. Future directions include exploring how social media can be used to enrich mentorship and networking opportunities in ophthalmology.

\section{Introduction}

Social media lies at the core of the millennial physician identity as this generation is the first to grow and train through the digital revolution.(1) With the onset of COVID-19 social distancing measures, traditional forms of professional engagement such as in-person conferences and networking opportunities became virtualized, and physicians took to social media to create online communities of discourse, mentorship, and education.(2). 
There have been multiple studies that have documented the role of social media in dissolving barriers and enhancing access to networking and mentorship opportunities among clinicians and trainees.(3-5) While professional engagement on social media in ophthalmology has been described for practice promotion and patient education, little is known about the role of social media as a tool for mentorship and support within the ophthalmology community.(6)

We conducted a survey study to assess the utilization of social media by ophthalmologists during the height of COVID-19 social distancing measures when in-person mentorship was less feasible. The goals of our study were to: 1) characterize the usage patterns of social media among ophthalmologists based on age, race, gender, and career stage; 2 ) explore respondents' motivations for using social media in the realm of personal and career development; and 3) understand the role of social media in its provision of equitable mentorship.

\section{Methods}

\section{Study setting and participant recruitment}

A 40-item questionnaire assessing the utilization of social media for personal and professional development in ophthalmology was developed based on themes extracted from a focused literature review on social media, training, mentorship, and personal and professional challenges in ophthalmology and medicine. The survey then distributed via social media channels including Instagram and Twitter to residents, fellows, and attendings in ophthalmology in Canada and the United States from November to December 2020. This study received full ethics committee approval and was conducted in accordance with the principles of the Declaration of Helsinki.

The anonymous online survey comprised of questions on demographic information including gender, race, age, country of training or practice, stage of career, number of children, and marital status. The survey then assessed challenges experienced in seven separate domains and whether social media was useful for overcoming those challenges (see Appendix 1 for survey questions). The seven domains assessed were: career planning and/or advancement, workplace discrimination, practice management, financial planning, work-life harmony, parenting, and mentorship.

Career planning and/or advancement encompassed promotion and/or compensation logistics; contract negotiation; fellowship application; board exams and certification; and seeking employment, leadership, public engagement, consulting, networking, and research opportunities.(7) Workplace discrimination included cultural, ethnic, religious, age or gender bias; sexual harassment; professional misconduct; interpersonal work conflicts; and institutional politics.(8) Practice management looked into practice philosophy, practice purchase and/or valuation, digital marketing, brand management, electronic medical record system management, human resources, shared expenses, remuneration logistics, and incorporation logistics.(7) Financial planning covered student loans, debt, investments, mortgage, and retirement plan. $(7,9)$ Work-life harmony encompassed interpersonal relationships, household 
responsibilities, balancing parenthood with work and training, caregiving, self-wellness, and burnout.(10, 11) Parenting included family planning, maternity and paternity leave, breastfeeding, pumping at work, and raising children.(10)

\section{Data analysis}

Statistical analyses were performed using GraphPad Prism Version 9.1.0 (GraphPad Software, Inc., CA, US). Standard descriptive analyses were used to summarize participant demographics with categorical variables in frequency and percent, and continuous variables in means and interquartile ranges.

Spearman's rank correlation, Kruskal-Wallis one-way analysis of variance (ANOVA), and two-sample ttests were used to test for differences in the role of social media between gender, race, age, and career stages. A p-value of less than 0.05 was statistically significant. Free-text responses were qualitatively coded using an inductive, line-by-line coding method to extract pertinent themes.

\section{Results}

\section{Demographic characteristics}

There were 149 participants ( $67.1 \%$ women, $32.2 \%$ men) in this study. Over half of participants were between the ages of 25 to 35 years old (56.4\%) with approximately one-third of respondents still in training (35.5\%) and one-quarter (25.5\%) in their first 5 years of practice. The majority of respondents were White (52.4\%) or Asian (32.2\%). Over two-thirds (69\%) of respondents were married, and approximately half had children (49\%). Anterior segment, cornea, and refractive surgery was the most represented subspecialty (26\%), and private group was the most common practice setting. All demographic characteristics are listed in Supplementary Table 1.

\section{Characteristics of social media usage}

The overwhelming majority of respondents $(94 \%)$ reported having a professional social media account with the top three most popular platforms being Instagram (25.2\%), Linkedln (22.6\%), and Facebook (19.6\%). The majority (64\%) of participants reported spending at least one hour daily on social media with nearly one-fifth (19\%) spending more than 2 hours per day. The five most common reasons respondents reported using social media were: to stay in touch with family, to promote their practice and/or professional services, to educate patients and/or the public about ophthalmology, to share interesting clinical and/or surgical cases with colleagues in their field, and to find mentorship and/or networking opportunities (Figure 1).

\section{Using social media to overcome challenges in personal and professional domains by gender}

While workplace discrimination was one of the lowest reported challenges overall, women were more likely to experience workplace discrimination compared to men $(p<0.01)$ with gender bias cited as the 
most common reason for discrimination (Figure 2). Women were also more likely to experience work-life disharmony compared to men $(p<0.05)$. In navigating those challenges, women reported social media to be more useful for overcoming challenges related to workplace discrimination $(p<0.01)$, work-life disharmony $(p<0.001)$, parenting $(p<0.0001)$, and mentorship $(p<0.05)$ compared to men. Women were also more likely to utilize social media to discuss and support gender issues compared to men $(p<0.05)$. These findings are summarized Table 1. 
Table 1

Reported challenges in professional and personal domains and perceived utility of social media for overcoming those challenges by gender, race, age, and career stage. Kruskal-Wallis one-way analysis of variance was used to analyze these domains. (*denotes statistical significance, underlined group denotes the group that were more likely to experience the challenge).

\begin{tabular}{|c|c|c|c|}
\hline & $\begin{array}{l}\text { Gender } \\
\text { ( } p \text { value) }\end{array}$ & $\begin{array}{l}\text { Age } \\
(p \\
\text { value) }\end{array}$ & $\begin{array}{l}\text { Career } \\
\text { ( } p \text { value) }\end{array}$ \\
\hline $\begin{array}{l}\text { Time spent on social } \\
\text { media }\end{array}$ & 0.3265 & $0.0110 *$ & 0.1069 \\
\hline \multicolumn{4}{|l|}{$\begin{array}{l}\text { Career planning and/or } \\
\text { advancement }\end{array}$} \\
\hline Challenges experienced & 0.9264 & 0.1909 & 0.0465 (trainee vs. late career: $p=0.0396)^{\star}$ \\
\hline $\begin{array}{l}\text { Challenges overcome with } \\
\text { social media }\end{array}$ & 0.1289 & 0.3955 & 0.1789 \\
\hline \multicolumn{4}{|l|}{ Workplace discrimination } \\
\hline Challenges experienced & $0.0021^{*}$ & 0.2419 & 0.5558 \\
\hline $\begin{array}{l}\text { Challenges overcome with } \\
\text { social media }\end{array}$ & $0.0028^{*}$ & 0.9530 & 0.8272 \\
\hline \multicolumn{4}{|l|}{ Practice management } \\
\hline Challenges experienced & 0.1732 & $0.0027^{*}$ & $\begin{array}{l}<0.0001 \text { (early career vs. trainee: } p=0.0176 \text {; late } \\
\text { career vs. trainee: } p<0.0001)^{\star}\end{array}$ \\
\hline $\begin{array}{l}\text { Challenges overcome with } \\
\text { social media }\end{array}$ & 0.7798 & $0.0143^{\star}$ & 0.2424 \\
\hline \multicolumn{4}{|l|}{ Financial planning } \\
\hline Challenges experienced & 0.6703 & 0.5720 & 0.0252 (trainee vs. late career: $p=0.0405)^{\star}$ \\
\hline $\begin{array}{l}\text { Challenges overcome with } \\
\text { social media }\end{array}$ & 0.7241 & 0.5207 & $\begin{array}{l}0.0446 \text { (early career vs. trainee: } p=0.032 \text {; late } \\
\text { career vs. trainee: } p=0.033)^{\star}\end{array}$ \\
\hline \multicolumn{4}{|l|}{ Work-life harmony } \\
\hline Challenges experienced & $0.0320 *$ & $0.0459 *$ & 0.1353 \\
\hline $\begin{array}{l}\text { Challenges overcome with } \\
\text { social media }\end{array}$ & $0.0005^{\star}$ & 0.1727 & 0.2096 \\
\hline \multicolumn{4}{|l|}{ Parenting } \\
\hline Challenges experienced & 0.0617 & 0.2093 & 0.0428 (early vs. late career: $p=0.0356$ )* \\
\hline $\begin{array}{l}\text { Challenges overcome with } \\
\text { social media }\end{array}$ & $<0.0001^{\star}$ & 0.111 & 0.1554 \\
\hline
\end{tabular}




\begin{tabular}{|llll|}
\hline & $\begin{array}{l}\text { Gender } \\
\text { (p value) }\end{array}$ & $\begin{array}{l}\text { Age } \\
\text { (p } \\
\text { value) }\end{array}$ & $\begin{array}{l}\text { Career } \\
\text { (p value) }\end{array}$ \\
\hline Mentorship & & & \\
\hline Provided on social media & 0.1130 & $0.0361^{*}$ & 0.2271 \\
\hline Received on social media & 0.8121 & 0.1380 & 0.7187 \\
\hline $\begin{array}{l}\text { Challenges overcome with } \\
\text { social media }\end{array}$ & $<0.0301^{*}$ & 0.4311 & 0.1334 \\
\hline $\begin{array}{l}\text { Using social media to overcome challenges in personal and } \\
\text { professional domains by age }\end{array}$
\end{tabular}

Participants were divided into two mutually exclusive age groups: younger (under age 45) and older (over age 45). Younger respondents were more likely to report inexperience with practice management $(p<0.01)$ and challenges with work-life harmony $(p<0.05)$ compared to older respondents. Younger respondents also spent more time on social media than older respondents $(p<0.01)$, and the former were also more likely to turn to social media as a tool to overcome obstacles related to practice management compared to older respondents $(p<0.01)$. Older respondents were more likely to utilize social media as a medium to provide mentorship to students, trainees, and/or colleagues in ophthalmology than younger respondents $(p<0.05)$. These findings are summarized in Table 1 and Figure 3.

\section{Using social media to overcome challenges in personal and professional domains by career stage}

Participants were divided into three mutually exclusive career stages: trainees (residents and fellows), early career (0-10 years in practice), or late career (11 or more years in practice). Compared to late career ophthalmologists, trainees were more likely to report difficulties with career advancement $(p<0.05)$ and financial planning $(p<0.05)$. In addition, early $(p<0.05)$ and late career $(p<0.0001)$ ophthalmologists perceived greater challenges with practice management compared to trainees. Among ophthalmologists who were in practice, early career ophthalmologists were more likely to report parenting challenges than late career ophthalmologists $(p<0.05)$. Social media was not found to have any benefits in overcoming any of these aforementioned challenges. These findings are summarized in Table 1 and Figure 4.

\section{Qualitative data analysis}

Seven themes were extracted from the free-text responses to the question "Is there anything else you think we should know about how and why you integrate social media into your career and/or personal life?" There were five positively oriented themes: promotion of career-development opportunities, 
community and networking, education, mentorship, and lifestyle recommendations; and two negatively oriented themes: misinformation and younger audience bias.

Participants commented on the ability of social media to allow for rapid and expansive amplification of career advancement and learning opportunities, including connecting with a larger audience of individuals who may not typically be exposed to such information. In particular, they found social media to be beneficial for networking, community building, fostering education, and facilitating mentorship. Several comments touched on the power of social media for connecting geographically and socially distant individuals. These connections can transcend the professional domain and may be protective against feelings of loneliness and burnout.

"Social media has helped me to stay in touch with mentors and mentees, as well as following the career journeys of peers and colleagues. I love to teach, and Instagram provides a great venue to build a collection of teaching materials that can be accessed by others in an asynchronous fashion. Particularly in 2020 , social media has played a strong role in my journey by helping me stay connected with others in my field and even develop new relationships, basically replacing (in an imperfect, more limited way) the type of organic connections that happen at in-person meetings." [Trainee]

"Particularly in 2020 , social media has played a strong role in my journey by helping me stay connected with others in my field and develop new relationships." [Trainee]

"Social media helps to find instant connection with colleagues that I would never otherwise meet. Practicing in small remote community limits access to professional communication and support. Sometimes [the] social media community fills the void of loneliness as well." [Early career ophthalmologist]

"Connecting with others in medicine and feeling like I am part of the house of medicine has helped prevent burnout." [Late career ophthalmologist]

"Great as a way to share interesting cases." [Late career ophthalmologist]

"As someone who is very set-in regard to being at the same practice for more than 20 years-social media is still quite important. I use social media for many of the projects I work on. For example, I am involved in many conferences and I will provide information/promotion of these events prior, and then post fun and interesting items after the conference-both educational-or just share fun photos from the events." [Late career ophthalmologist]

The less formal style of engagement fostered by many social media platforms also allows for levity, which is particularly evident through respondents' emphasis on "fun" and "creative" elements.

Participants commented on social media potentially being biased toward a younger audience, a finding that was also evidenced in our study with $81.9 \%$ of respondents younger than 45 years old. 
"To interact with other trainees in my field; for 'life hacks' [such as] cooking / organizing tips / ways to make life more efficient; for motivation, fashion, working out." [Trainee]

"It is a fun outlet and a way to connect and share." [Early career ophthalmologist]

"[Social media] is a little skewed towards students and trainees; it would be nice if more established ophthalmologists were more active on the platform." [Late career ophthalmologist]

Despite the advantages of social media, some respondents recognized its limitations as well. As social media can cater towards highly curated content, this can amplify both positive and negative voices.

"It is not the end all be all for me; simply an outlet to occasionally connect with new folks and be aware of opportunities that may not be physically immediately around me." [Trainee]

"Although social media can provide a community and network, I feel gender discrimination is rampant on these platforms. I choose not to engage or promote platforms that are full of misinformation and harassment." [Trainee]

"I have abstained from creating a professional social media account, because I can't see myself fitting in with the highly followed doctors I see on social media. I don't think that posting a highly manicured photo that makes myself look beautiful and that makes my life appear seemingly perfect is a service to students and trainees. I wish to see more doctors being authentic on social media before I integrate it into my own career." [Early career ophthalmologist]

"It is a double-edged sword." [Late career ophthalmologist]

\section{Discussion}

There is strong evidence supporting the value of mentorship in ophthalmology (12-14), and our study illuminates the diverse ways by which ophthalmologists use social media as a tool for personal and professional growth through mentorship, education, networking, and community support. We found significant differences in the personal and professional challenges that are faced by different demographic groups, as well as the ways in which social media may be harnessed to mitigate those challenges.

\section{Gender}

Our study revealed that women were more likely to report challenges with workplace discrimination and work-life harmony than men, and that social media was perceived to be useful in dealing with these challenges. The reasons why women reported more concerns with workplace discrimination and work-life harmony are likely multifactorial. Numerous studies have reported that compared to men, women physicians are more likely to experience burnout, especially those who encounter gender discrimination, gender biases, and barriers to professional advancement in the workplace.(15-17) 
Emerging evidence suggests that the percentage of women physicians has slowly risen globally over the past few decades, but the representation of women in surgical fields has not kept pace.(18) Women medical students who are interested in surgery are known to face complex systemic challenges such as gender discrimination, concerns of inequitable career advancement, and unfavourable professional policies regarding family planning and childbearing. $(10,19-21)$ The lack of surgeon role models and leadership representation,(22) concerns of gender pay gap,(23) academic promotion discrepancies,(24) and conflict with work-life harmony may also dissuade women from pursuing surgical specialties, and potentiate a sense of isolation for women who do follow these career paths. $(10,25)$

There are several factors that may be contributing to greater social media usage among women, trainees, and early career ophthalmologists as demonstrated in our study. These factors may be akin to those which led to the emergence of recent movements including \#WomenInMedicine, \#WomenInOphthalmology, \#IAmYourDoctor, and \#ILookLikeASurgeon and which pave the course for virtual communities of support that challenge hierarchical structures of power in medicine. ${ }^{21}$ Recent studies have found that social media provides a contemporary medium for women trainees to network, seek mentorship, and discuss strategies for achieving work-life harmony and success in the workplace. (5) Our finding that women in ophthalmology are turning to virtual communities for support regarding workplace discrimination and work-life harmony indeed aligns with the current body of literature.(26)

\section{Age and career stage}

Our study showed that younger respondents and trainees were more likely to report challenges with practice management and financial planning, respectively, compared to their more senior counterparts. Younger respondents were also more likely to turn to social media to seek guidance for practice management. Multiple studies have shown that practice management and financial literacy tend to be overlooked in medical education, and including these subjects in residency training is critical to ensuring graduating ophthalmologists have the financial competency in successfully managing a practice.(2729) Our study suggests that social media offers educational opportunities related to practice management for budding ophthalmologists. Thus, professional organizations, societies, and institutions may endeavour to fill this gap in practice management education using virtual platforms such as social media, which are also found to be more commonly used by younger respondents in our study.

\section{Strengths and limitations of our study}

Our study is the first to explore social media use among ophthalmologists, focusing on the role of social media in overcoming personal and professional challenges. The study population demonstrates heterogeneity in participant demographics and is the largest known study on social media in ophthalmology. Limitations include ascertainment, sampling, recall, and reporting bias which are common in survey studies. Despite these limitations however, we discovered novel insights, both positive and negative, into the usage patterns and role of social media among a diverse group of ophthalmologists. Our findings highlight several future directions including evaluation of usage patterns among a larger and more global cohort to assess the benefits of social media among underrepresented 
individuals in ophthalmology, as well as identifying ways to improve ophthalmology content on social media to fill in gaps and improve equity.

\section{Declarations}

\section{ACKNOWLEDGEMENTS}

We are thankful to BMC Vision and Millennial Eye for their support in distributing our survey.

\section{CONFLICT OF INTEREST}

Dagny Zhu and Neda Shamie have participated in programs associated with BMC Vision and Millennial Eye.

\section{FUNDING}

None.

\section{AUTHORS' CONTRIBUTIONS}

Bonnie He: Conceptualization, Methodology, Validation, Formal Analysis, Investigation, Data Curation, Writing - Original Draft, Reviewing/Editing, Visualization, Project Administration, Funding Acquisition.

Stuti Tanya: Conceptualization, Methodology, Validation, Writing - Reviewing/Editing, Visualization, Project Administration, Funding Acquisition.

Fiona Costello: Writing - Reviewing/Editing,

Femida Kherani: Writing - Reviewing/Editing.

Neda Shamie: Writing - Reviewing, Editing.

Dagny Zhu: Conceptualization, Methodology, Validation, Writing - Reviewing/Editing, Visualization, Project Administration, Funding Acquisition, Supervision.

\section{References}

1. Rolls K, Hansen M, Jackson D, Elliott D. How Health Care Professionals Use Social Media to Create Virtual Communities: An Integrative Review. J Med Internet Res 2016 Jun 16;18(6):e166. 
2. Topf JM, Williams PN. COVID-19, Social Media, and the Role of the Public Physician. Blood Purif 2021:1-7.

3. Luc JGY, Stamp NL, Antonoff MB. Social Media as a Means of Networking and Mentorship: Role for Women in Cardiothoracic Surgery. Semin Thorac Cardiovasc Surg 2018;30(4):487-495.

4. Wagner JP, Cochran AL, Jones C, Gusani NJ, Varghese TK,Jr, Attai DJ. Professional Use of Social Media Among Surgeons: Results of a Multi-Institutional Study. J Surg Educ 2018;75(3):804-810.

5. Luc JGY, Stamp NL, Antonoff MB. Social media in the mentorship and networking of physicians: Important role for women in surgical specialties. The American Journal of Surgery 2018;215(4):752760.

6. Al-Khersan H, Lazzarini TA, Fan KC, Patel NA, Tran AQ, Tooley AA, et al. Social media in ophthalmology: An analysis of use in the professional sphere. Health Informatics J 2020 Dec;26(4):2967-2975.

7. Badawy SM. Career planning and mentorship: a few key considerations for trainees. International journal of general medicine 2017;10:357-359.

8. Bruce AN, Battista A, Plankey MW, Johnson LB, Marshall MB. Perceptions of gender-based discrimination during surgical training and practice. Medical education online 2015;20:25923.

9. Shappell E, Ahn J, Ahmed N, Harris I, Park YS, Tekian A. Personal Finance Education for Residents: A Qualitative Study of Resident Perspectives. AEM education and training 2018;2(3):195-203.

10. Mulcahey MK, Nemeth C, Trojan JD, O'Connor MI. The Perception of Pregnancy and Parenthood Among Female Orthopaedic Surgery Residents. J Am Acad Orthop Surg 2019 Jul 15;27(14):527532.

11. Nair AG, Jain P, Agarwal A, Jain V. Work satisfaction, burnout and gender-based inequalities among ophthalmologists in India: A survey. Work 2017;56(2):221-228.

12. Nassrallah G, Arora S, Kulkarni S, Hutnik CML. Perspective on a formal mentorship program in ophthalmology residency. Can J Ophthalmol 2017 Aug;52(4):321-322.

13. Olivier MMG, Forster S, Carter KD, Cruz OA, Lee PP. Lighting a Pathway: The Minority Ophthalmology Mentoring Program. Ophthalmology 2020;127(7):848-851.

14. Tsai JC, Lee PP, Chasteen S, Taylor RJ, Brennan MW, Schmidt GE. Resident Physician Mentoring Program in Ophthalmology: The Tennessee Experience. Arch Ophthalmol 2006;124(2):264-267.

15. Patel RS, Bachu R, Adikey A, Malik M, Shah M. Factors Related to Physician Burnout and Its Consequences: A Review. Behavioral sciences (Basel, Switzerland) 2018;8(11):98.

16. McMurray JE, Linzer M, Konrad TR, Douglas J, Shugerman R, Nelson K. The work lives of women physicians results from the physician work life study. The SGIM Career Satisfaction Study Group. Journal of general internal medicine 2000;15(6):372-380.

17. Chesak SS, Cutshall S, Anderson A, Pulos B, Moeschler S, Bhagra A. Burnout Among Women Physicians: a Call to Action. Curr Cardiol Rep 2020 May 29;22(7):45-6. 
18. de Costa J, Chen-Xu J, Bentounsi Z, Vervoort D. Women in surgery: challenges and opportunities. IJS Global Health 2018;1(1).

19. Seemann NM, Webster F, Holden HA, Moulton CA, Baxter N, Desjardins C, et al. Women in academic surgery: why is the playing field still not level? Am J Surg 2016 Feb;211(2):343-349.

20. Silver JK, Slocum CS, Bank AM, Bhatnagar S, Blauwet CA, Poorman JA, et al. Where Are the Women? The Underrepresentation of Women Physicians Among Recognition Award Recipients From Medical Specialty Societies. PM R 2017 Aug;9(8):804-815.

21. Valsangkar N, Fecher AM, Rozycki GS, Blanton C, Bell TM, Freischlag J, et al. Understanding the Barriers to Hiring and Promoting Women in Surgical Subspecialties. J Am Coll Surg 2016;223(2):387398.e2.

22. Shah DN, Volpe NJ, Abbuhl SB, Pietrobon R, Shah A. Gender characteristics among academic ophthalmology leadership, faculty, and residents: results from a cross-sectional survey. Ophthalmic Epidemiol 2010;17(1):1-6.

23. Jia JS, Lazzaro A, Lidder AK, Elgin C, Alcantara-Castillo J, Gedde SJ, et al. Gender Compensation Gap for Ophthalmologists in the First Year of Clinical Practice. Ophthalmology 2020.

24. Tanya SM, He B, Tang J, He P, Zhang A, Sharma E, et al. Research productivity and impact of Canadian academic ophthalmologists: national trends in $\mathrm{H}$-index, gender, subspecialty, and faculty appointment. Canadian Journal of Ophthalmology.

25. Carr PL, Raj A, Kaplan SE, Terrin N, Breeze JL, Freund KM. Gender Differences in Academic Medicine: Retention, Rank, and Leadership Comparisons From the National Faculty Survey. Academic medicine: journal of the Association of American Medical Colleges 2018;93(11):1694-1699.

26. Shillcutt SK, Silver JK. Social Media and Advancement of Women Physicians. N Engl J Med 2018;378(24):2342-2345.

27. McDonnell PJ, Kirwan TJ, Brinton GS, Golnik KC, Melendez RF, Parke DW,2nd, et al. Perceptions of recent ophthalmology residency graduates regarding preparation for practice. Ophthalmology 2007 Feb;114(2):387-391.

28. Dawson B, Carter K, Brewer K, Lawson L. Chart smart: a need for documentation and billing education among emergency medicine residents? The western journal of emergency medicine 2010;11(2):116-119.

29. Austin RE, von Schroeder H,P. How accurate are we? A comparison of resident and staff physician billing knowledge and exposure to billing education during residency training. Canadian journal of surgery.Journal canadien de chirurgie 2019;62(5):340-346.

\section{Figures}




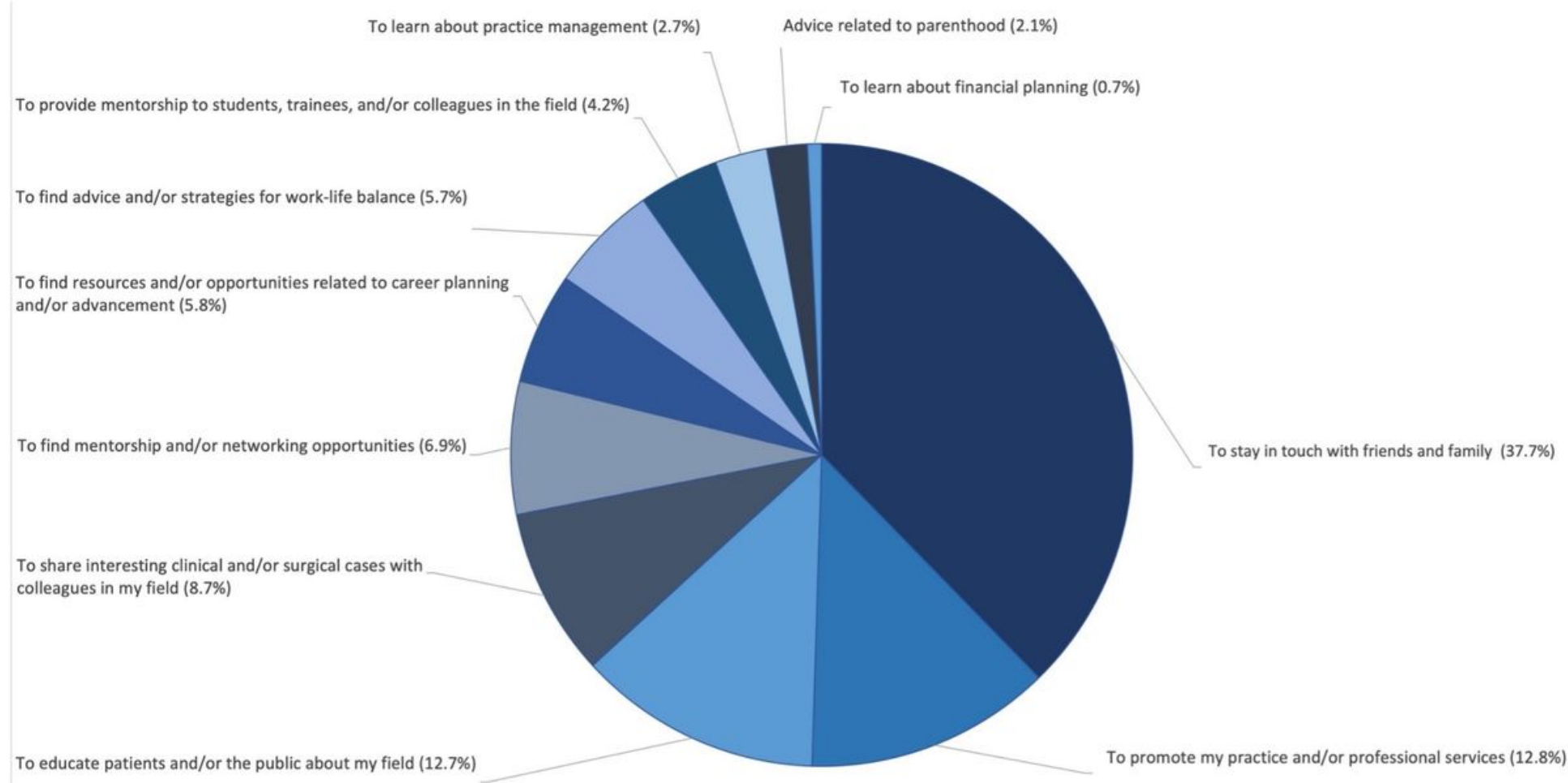

\section{Figure 1}

Reasons for social media use among respondents. 


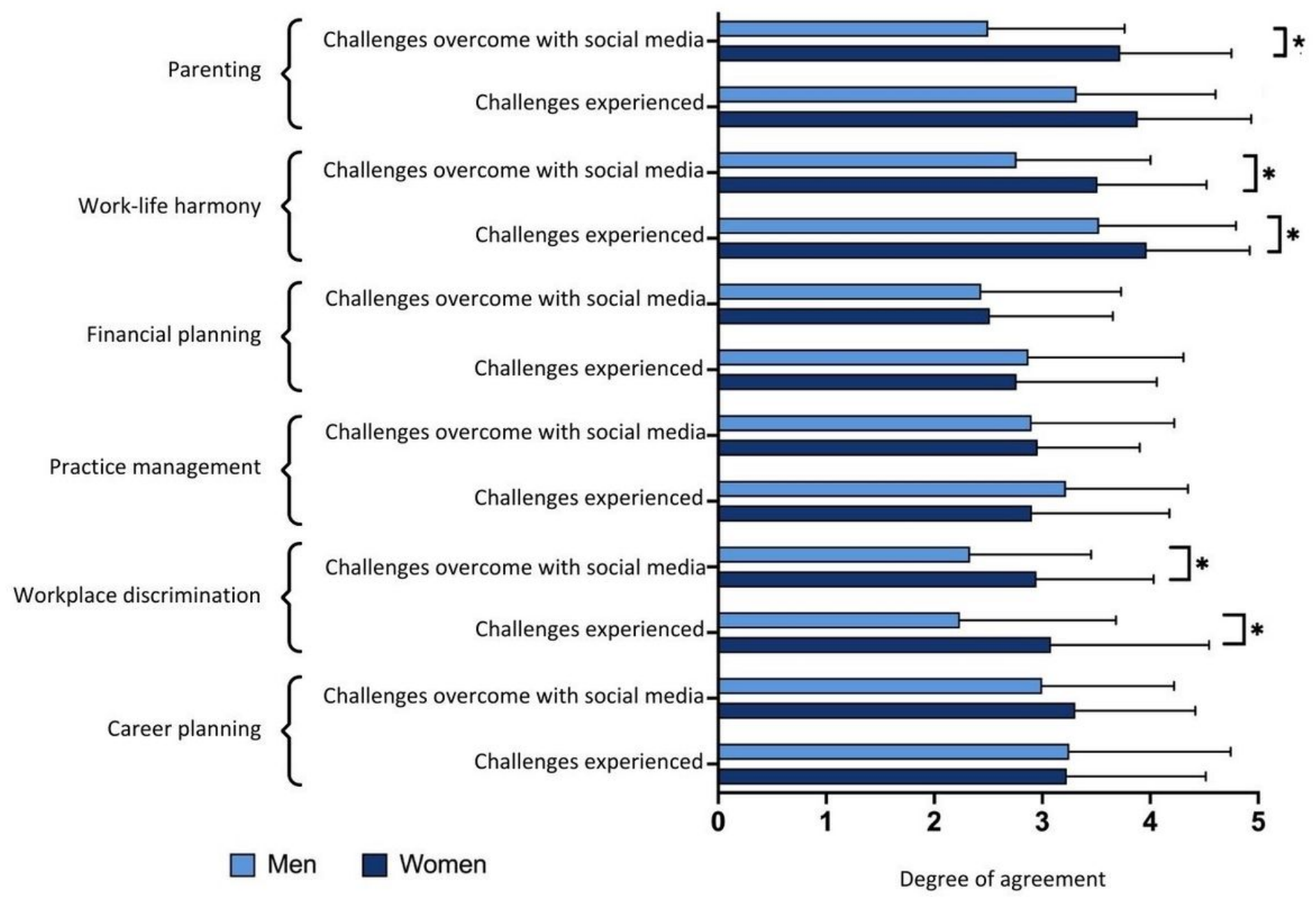

\section{Figure 2}

Challenges experienced and overcome with social media for gender category. Degree of agreement: 1 strongly disagree, 2 - somewhat disagree, 3 - neither agree nor disagree, 4 - somewhat agree, 5 strongly agree. (*denotes statistical significance). 


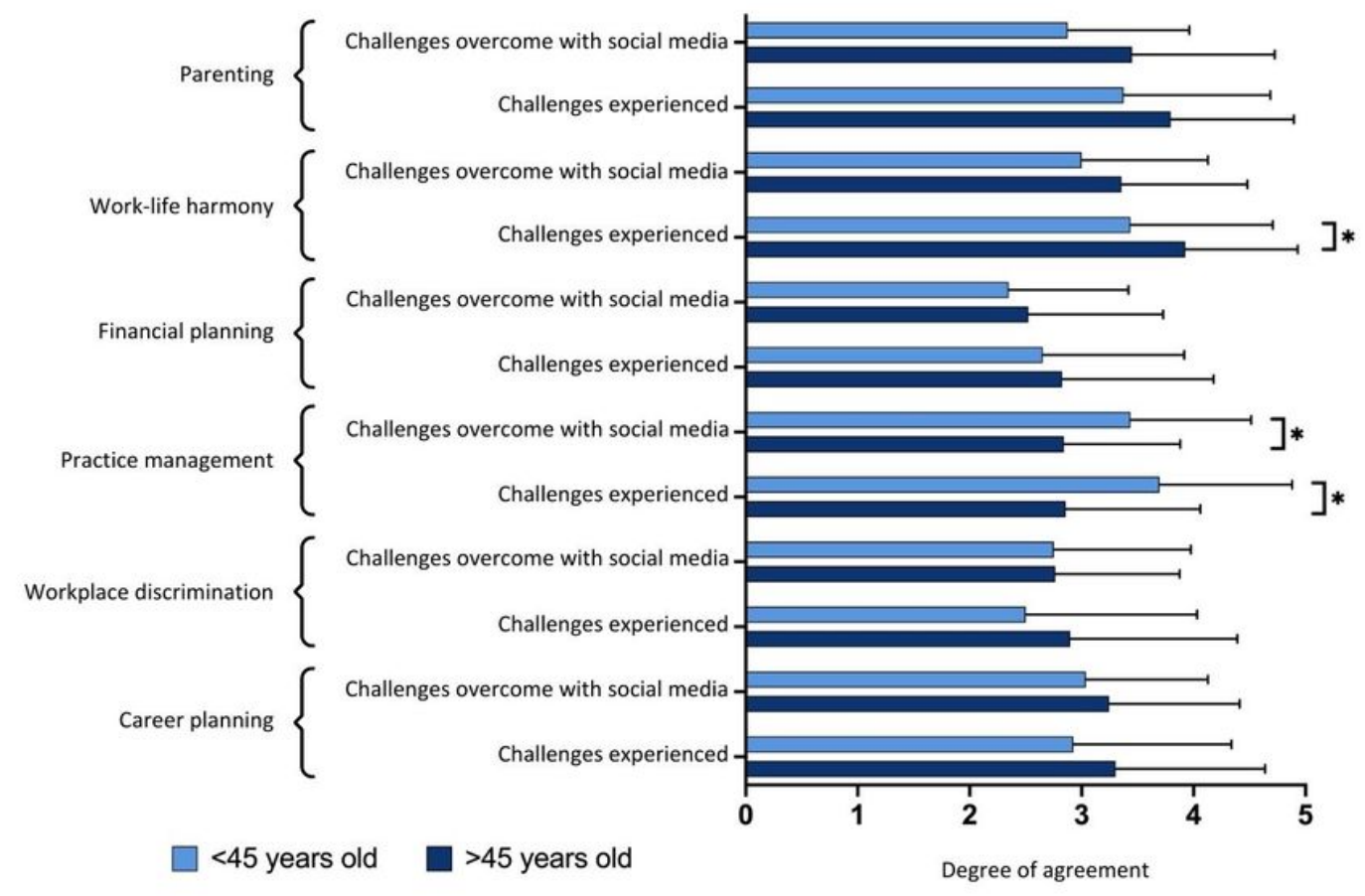

\section{Figure 3}

Challenges experienced and overcome with social media for age category. Degree of agreement: 1 strongly disagree, 2 - somewhat disagree, 3 - neither agree nor disagree, 4 - somewhat agree, 5 strongly agree. (*denotes statistical significance). 


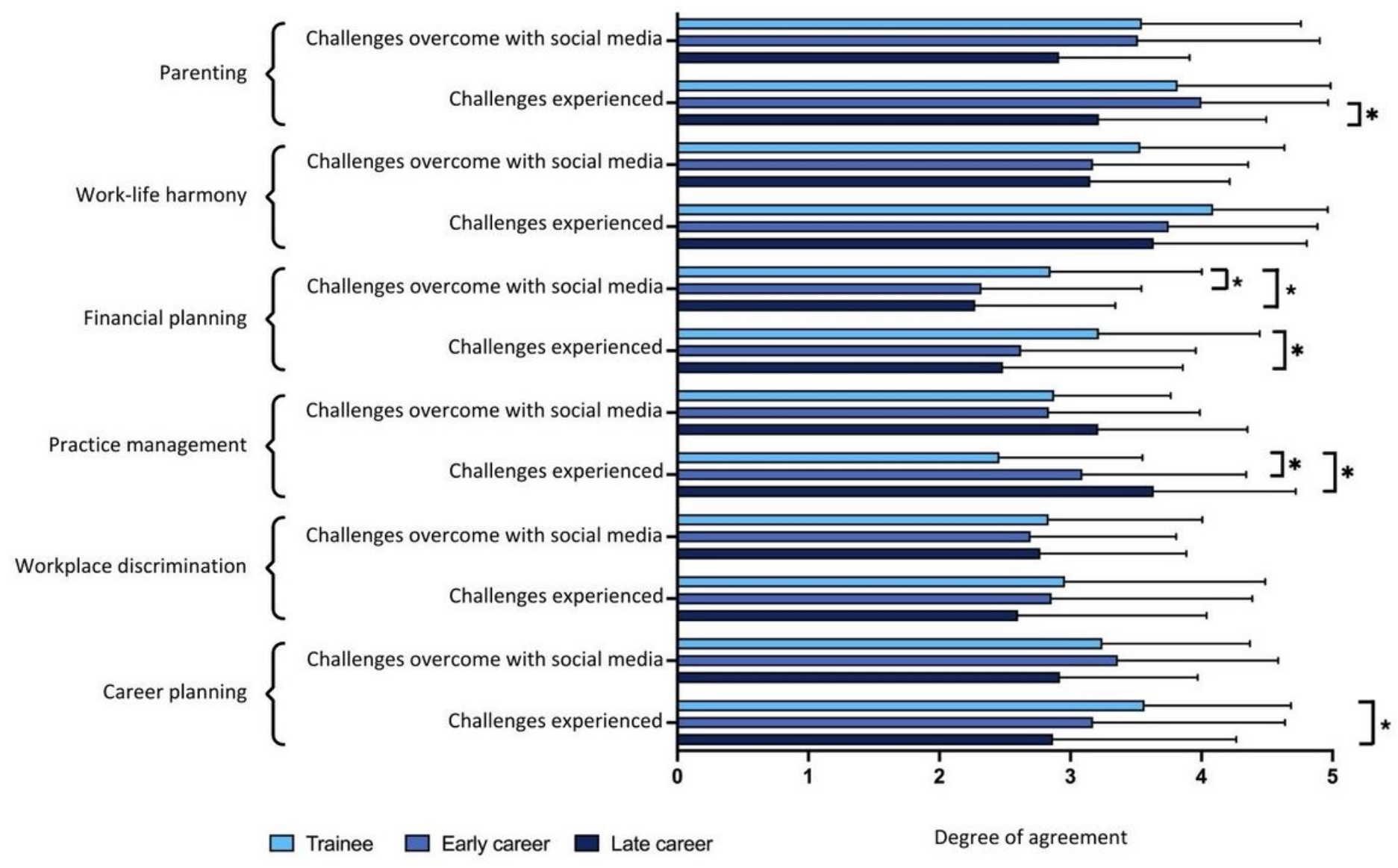

\section{Figure 4}

Challenges experienced and overcome with social media for career stage category. Degree of agreement: 1 - strongly disagree, 2 - somewhat disagree, 3 - neither agree nor disagree, 4 - somewhat agree, 5 strongly agree. (*denotes statistical significance).

\section{Supplementary Files}

This is a list of supplementary files associated with this preprint. Click to download.

- SupplementaryTable1.docx

- WIOQualtricssurvey.pdf 